\title{
Experimental analysis and development of an in-house CFD condensation hood model
}

\author{
Mieszko Tokarski ${ }^{1,2,3}$ (1) $\cdot$ Arkadiusz Ryfa $^{1}$ - Piotr Bulinski ${ }^{1} \cdot$ Marek Rojczyk ${ }^{1} \cdot$ Krzysztof Ziarko $^{3}$ - Ziemowit Ostrowski ${ }^{1}$. \\ Andrzej J. Nowak ${ }^{1}$
}

Received: 22 April 2020 / Accepted: 28 June 2021 / Published online: 16 July 2021

(C) The Author(s) 2021

\begin{abstract}
An existing condensation hood has been numerically investigated using $k$ - $\varepsilon$ turbulence and species transport models. Due to the geometrical complexity of the appliance, two additional mathematical models were introduced with the use of User Defined Functions (UDFs). They were a model of a fan and a model of the internally finned pipes of a heat exchanger. The latter also involved a condensation model of steam implemented by mass and energy source terms. Such an approach allowed us to avoid troublesome two-phase flow simulation and thus significantly reduced the computational effort. Based on the results provided by the numerical model, potential improvements of the heat exchanger were proposed and implemented into a second, modified numerical model. Reduction of the number of the pipes by $25 \%$ is the most important change of the developed device. Its negative effect on condensation efficiency was to be compensated by improvements of steam flow in the device. Once the modifications had been evaluated, the prototype of the device was built and tested experimentally. Both the numerical and experimental results agree and show that, the modified condensation hood is comparable to the original construction in terms of condensation efficiency, despite the significant heat transfer surface area reduction.
\end{abstract}

Keywords Condensation hood $\cdot$ Numerical model $\cdot$ User-defined function $\cdot$ Heat transfer $\cdot$ Heat exchanger

\section{Nomenclature}

\section{Latin symbols}

$\dot{H} \quad$ Enthalpy $\left[\mathrm{W} / \mathrm{m}^{3}\right]$

$\dot{m} \quad$ Mass flow rate $[\mathrm{kg} / \mathrm{s}]$

$\dot{Q} \quad$ Heat rate [W]

A Area $\left[\mathrm{m}^{2}\right]$

\section{Highlights}

- Developed condensation and heat transfer model with use of user-defined functions

- Developed numerical models - of already existing device and a new prototype based on the previous analysis

- Validation of both numerical models

- Numerical and experimental comparison of the both constructions

Mieszko Tokarski

mieszko.tokarski@polsl.pl

1 Department of Thermal Engineering, Silesian University of Technology, 44-100 Gliwice, Poland

2 Department of Fuels Technology, AGH University of Science and Technology, al. Mickiewicza 30, 30-059 Kraków, Poland

3 Retech sp. z o. o., 39-300 Mielec, Poland

$\begin{array}{ll}c & \text { Specific heat }[\mathrm{J} /(\mathrm{kg} \mathrm{K})] \\ h_{f g}^{*} & \begin{array}{l}\text { Modified latent heat of vaporization of water } \\ {[\mathrm{J} / \mathrm{kg}]}\end{array} \\ \mathrm{L} 1-\mathrm{L} 2 & \text { Left-hand side baffles } \\ \mathrm{p} & \text { Pressure [Pa] } \\ \mathrm{R} & \text { Thermal resistance }[(\mathrm{m} 2 \mathrm{~K}) / \mathrm{W}] \\ \mathrm{R} 1-\mathrm{R} 2 & \text { Right-hand side baffles } \\ \mathrm{T} & \text { Temperature }[\mathrm{K}] \mathrm{T} 1-\mathrm{T} 8 \text { thermocouples } \\ \mathrm{V} & \text { Volume [m3] } \\ \mathrm{w} & \text { Mass fraction }[-] \\ \mathrm{Greek} \text { symbols } \\ \beta & \left.\text { Angle of attack [ }{ }^{\circ}\right] \\ \eta & \text { Condensation efficiency [\%] } \\ \varphi & \text { Relative humidity [\%] } \\ \varepsilon & \text { Correction factor [-] }\end{array}$

$\begin{array}{ll}\text { Subscripts } & \\ \text { air } & \text { Air } \\ \text { amb } & \text { Ambient } \\ \text { cond } & \text { Condensate } \\ \mathrm{H} 2 \mathrm{O} & \text { Water } \\ \text { in } & \text { Inlet } \\ \text { max } & \text { Maximum }\end{array}$




$\begin{array}{ll}\text { out } & \text { Outlet } \\ \text { ref } & \text { Reference value } \\ \text { steam } & \text { Steam } \\ \text { wall } & \text { Wall }\end{array}$

\section{Abbreviations}

BC Boundary Condition

CFD Computational Fluid Dynamics

Exp Experiment

HE Heat Exchanger

UDF User Defined Function

\section{Introduction}

Contemporary gastronomy strives to meet customer expectations regarding the quality of dishes and service. It is also supported by technology which comes with various devices that facilitate the preparation of high quality dishes. Combisteamers are good examples of such devices. Their semiautomated cooking modes - steam, hot air, and combination of both - allow for roasting, baking, steaming, defrosting, reheating, etc. Such versatility has led to a situation where combi-steamers have become an integral part of kitchen equipment and nowadays are widely used [1].

Combi-steamers, however, have one major drawback they produce significant amount of steam combined with an odor that negatively affects the staff and meals if it is released by the oven directly to the kitchen [2]. Stationary steam vents and so-called condensation hoods prevent such a situation.

Condensation hoods capture steam produced by the combi-steamers and condense it. The condensate is then returned to the oven by gravitational forces or goes directly to a drain. Hence, additional mobility of the oven is provided so any stationary infrastructure becomes unnecessary. Such mobility brings an additional benefit: combi-steamers with condensation hoods can be used in places without proper infrastructure such as, for example, steam vents that simply drain the steam outside the work zone. This is why condensation hoods seem to be a much more convenient solution.

When a condensation hood is used instead of steam vents, in the ideal case the whole of the steam produced by the combi-steamer should be condensed and returned to the oven. Otherwise excessive water vapor will probably contaminate the work zone. This is why condensation hoods should be as efficient as possible. Designing such appliances requires advanced engineering tools, such as computational fluid dynamics (CFD). They allow for a preliminary diagnosis of the prototype before it is constructed and installed [3]. However, any CFD model always requires validation.
Despite the fact that this type of device has an established position on the market, there are no known comprehensive scientific publications devoted to it. This means that condensation hoods are still not well-examined devices. Steam condensation requires a heat exchanger, the design of which makes this element the most demanding and expensive part of the condensation hood. For this reason, the investigation of such appliances in terms of heat transfer and condensation efficiency was necessary [4-6].

Analysis of the unit processes taking place in this device are already described in the literature related to other apparatus/appliances [7]. The most important phenomena in terms of condensation efficiency are: the model of condensation of the air-steam mixture coupled with the species transport process [8-10], and the fluid flow and heat transfer in internally-finned pipes [11-18]. Analytical models of the heat and mass transfer through such a tubes are not universal equations known from a handbooks like [19], so their application is constrained by the flow conditions and geometrical properties. For this reason, a new model that fit our needs and expectations was developed and briefly described in this paper. Geometrical structure of a heat exchanger is mostly compact and complex, which makes discretization of such domain and further computations problematic. This applies in particular to small but important elements, like finned pipes, in terms of heat transfer and pressure drop [20-23].

One type of condensation hood, currently produced by industry and frequently used in the gastronomy, has already been tested in various working conditions [24]. The previously carried out measurements allowed us to develop a simplified model of the main processes occurring in this device and validate that model. This analysis also provided the basis for the development of potential improvements. In this work, Section 3, constitutes a very condensed description of the performed experiments. A literature study showed that, there is no model allowing for a rapid and accurate modelling of a condensation process in the analyzed device. For this reason, a novel condensation and heat transfer model is proposed in this work, so a two-phase flow with phase change process can be replaced by a much simpler model of a single-phase (i.e. gas phase) flow. The liquid phase, which amount is a result of the local energy balance, is moving out from the computational domain without any phase change. Such an approach leads to a significant computational cost reduction.

In the current paper, analysis of the condensation hood is extended and two different numerical models are proposed with the use of Ansys Fluent. The first one, related to the existing device, is employed for diagnostic purposes, while the second model suggests some changes to the heat exchanger. The authors of this manuscript are also working on a third model presenting a completely new concept of 


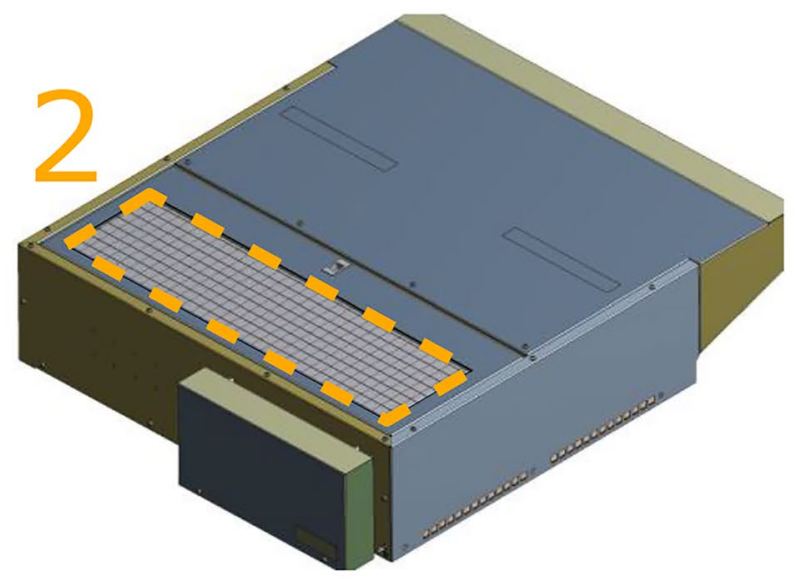

(a)

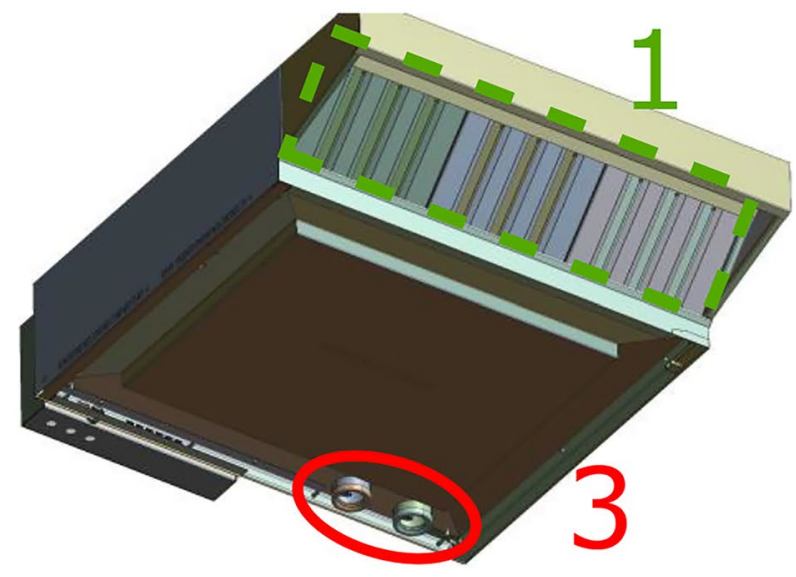

(b)

Fig. 1 Condensation hood: (a) Top view; (b) - bottom view. 1 - air inlet; 2 - air outlet; 3 - steam inlets

the heat exchanger. This, however, will be the subject of a separate paper.

Both the proposed models include the geometry of the condensation hood. The condensation hood is equipped with a centrifugal fan having complex geometry, so it is replaced by a separate mathematical model implemented as a user defined function (UDF). A species transport model [25] is used to model the flow of the air-steam mixture. Another UDF is proposed to avoid the simulation of the difficult process of condensated steam removal from the computational domain. Such an approach does not affect the accuracy of the solution since volume occupied by the condensate is negligible compared to the volume occupied by the steam. Due to the mesh requirements, heat exchanger also needed some simplifications. Hence, the pipes of the heat exchanger were replaced by another UDF formulated as special boundary conditions (BCs). The $k-\varepsilon$ model was used for turbulence simulation [25].

\section{Condensation hood: operation principle}

Figure 1 presents a condensation hood. The device is equipped with a fan that sucks humid air from the environment through the inlet (number 1 in Fig. 1b) and pulls it through the heat exchanger located inside, where steam condensation occurs. The condensation hood is also supplied with steam by steam inlets (number 3 in Fig. 1b). The steam is mixed with the air at the fan inlet. Humid air pulled through the appliance is finally released back to the environment through the air outlet (number 2 in Fig. 1a).

\section{Experimental setup and measurement procedure}

The analysis of the original condensation-hood, described in detail in our previous work [24], consists of a mathematical model, that is based on three balances written for steady-state: mass balance of dry air, moisture balance and energy balance. Fig. 2 presents condensation hood's balance

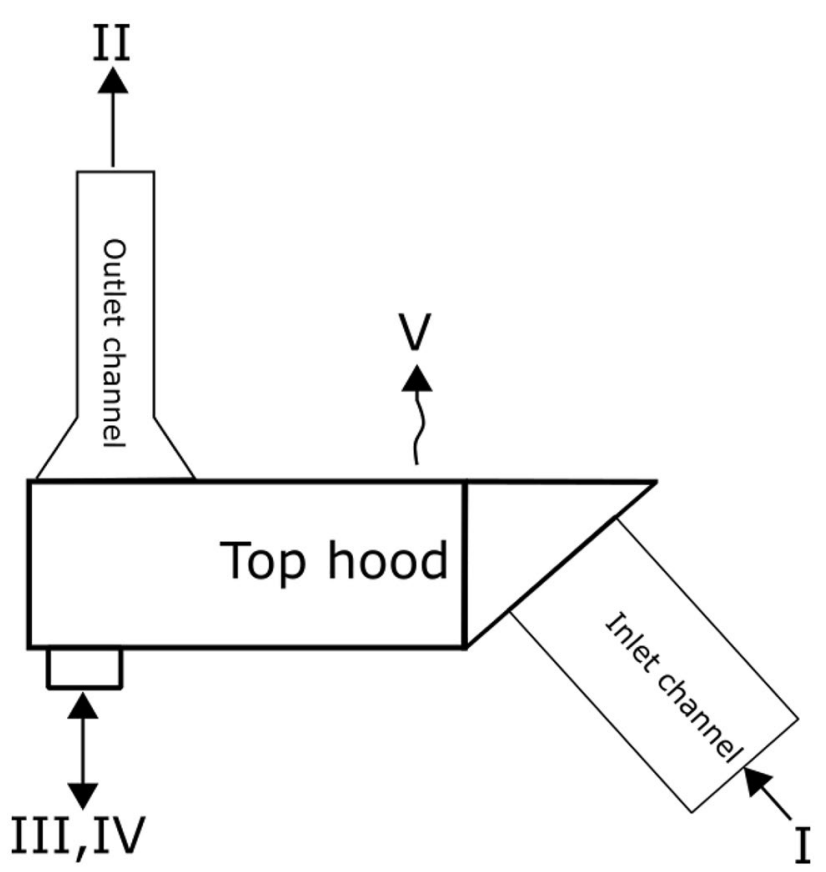

Fig. 2 The hood's inlets, outlets and locations of measuring points 
elements taken into account in the mathematical model $I-V$ as well as measured quantities:

I - air inlet: air temperature, relative humidity and velocity.

II - air outlet: air temperature, relative humidity and velocity.

III - condensate outlet: mass and time.

IV - steam inlet: steam temperature.

$\mathrm{V}$ - heat losses: temperature of the housing.

Proper measurement of the velocity of the air at the inlet and outlet was problematic, thus an additional channels were introduced (see Fig. 2. Hence, velocity fields became more uniform and the measurements more reliable.

The condensation hood was examined in a three different cases:

Case A: A low-powered steam generator $(3.4 \mathrm{~kW})$.

Case B: A high-powered steam generator $(27 \mathrm{~kW})$.

Case C: A dedicated combi-steamer.

Figure 3 presents a general scheme of the steam generators (case $A$ and case B). They consist of a water tank $b$ and an electric heater $d$. The condensation hood $a$ is connected with the water tank $b$ by the fittings $e$. The low-powered steam generator was equipped with hot water supply valve $c$ in order to achieve steady-state by extending measurement time.

Low-powered steam generator (case A) provided known and constant over time mass flow rate of the steam delivered to the condensation hood. In case of the high power steam

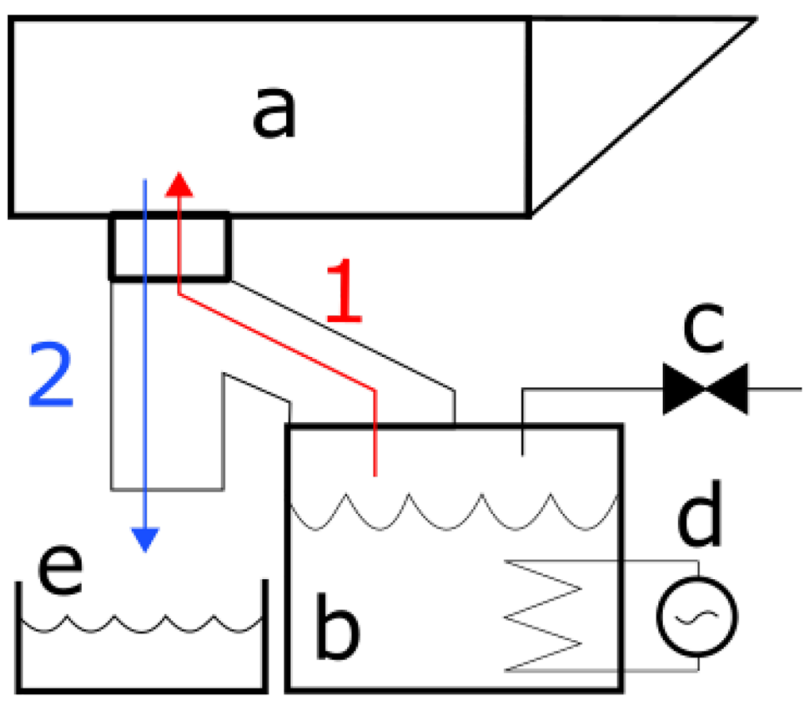

Fig. 3 Scheme of the steam generators: $\mathbf{a}$-condensation-hood; $\mathbf{b}-$ water tank (or a combi-steamer); c-water supply valve; $\mathbf{d}$-electric immersion heater; $\mathbf{e}$ - condensate container; 1 - steam; 2 - condensate generator case $B$, a steady-state was achieved much quicker than in remaining cases, so refilling the water tank was redundant.

The steam generators provided known input into the condensation hood, which was crucial during validation of the mathematical model. During the experiments, the mass flow rate of the steam was typical for the condensation hood case $A$. It also allowed for verification of the chosen measurement methodology. High-powered steam generator (case B) enabled assessment of the maximum condensation capacity of the device by applying steam flow rate greatly exceeding typical conditions. In case of the combi-steamer (case $C$ ) the heater power $d$, along with the water supply $c$ flow rate, are unknown, and the water tank $b$ is, in this case, the combi-steamer itself.

The condensation hood condensates the steam and returns it back to the combi-steamer (point III). Rest of the moisture remains in form of the vapour and at the end is released to the environment $I I$ with humid air. The condensation hood is supplied with a mixture of steam and air by the oven. Hence, any reliable and non-invasive measurement of the flow rate at point $I V$ is very difficult.

\section{Computational model}

The model was developed with use of Ansys Fluent software. It covers steam and air flow, steam condensation and heat transfer in the condensation hood. Computations were performed in steady-state with enabled gravitation. As a pressure-velocity coupling SIMPLE scheme was used due to its computational efficiency and relatively simple flow to simulate lacking complex swirls and high velocity gradients. Next second order upwind discretization schemes of pressure, turbulence, species, and energy were set. Gradient discretization was set as least squares cell based, because majority of the mesh consists of hexahedral elements.

The most important assumption of the model is that the condensed steam (the condensate) is removed from the domain instead of being modeled. Such an approach allows for the use of a species transport model and greatly enhances calculation performance. The $k-\varepsilon$ model has been used for turbulence modelling, due to the dominant air velocity at around $10 \mathrm{~m} / \mathrm{s}$ in the inlet part $I$ and outlet part III shown in Fig. 4. The steam flowing in the heat exchanger II slows down rapidly to less than $1 \mathrm{~m} / \mathrm{s}$, which initially caused solution stability problems. However, once the laminar zone was set in the steam side of the heat exchanger $I I$, the stability problems were resolved.

Continuity equation solved by the Fluent in the Species Transport model takes the form

$\frac{\partial}{\partial t}\left(\rho Y_{i}\right)+\nabla \cdot\left(\rho \vec{v} Y_{i}\right)=-\nabla \cdot \vec{J}_{i}+R_{i}+S_{i}$ 
Fig. 4 Geometry: (a) Top view; (b)—bottom view. I-inlet part; II-heat exchanger (steam side); III-heat exchanger

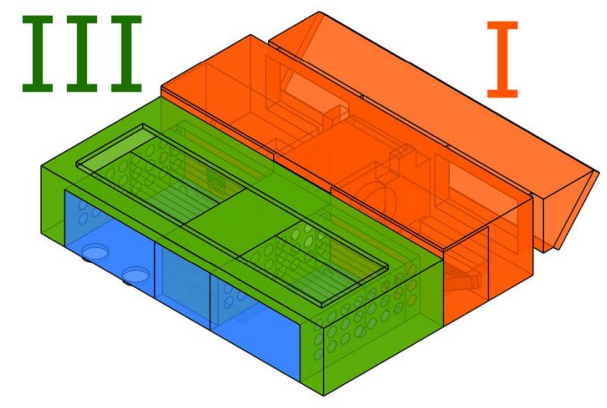

(a)

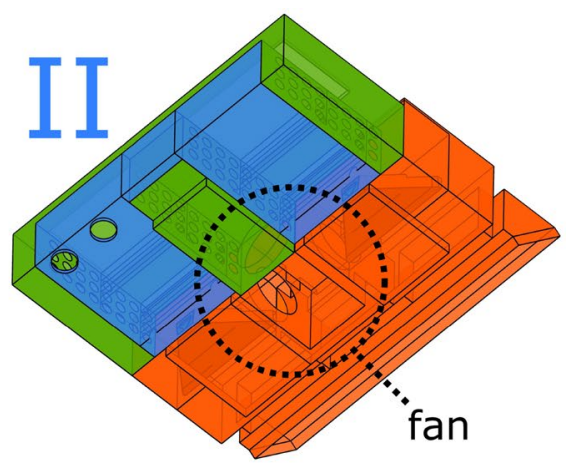

(b) where $Y_{i}$ is the $i-t h$ species mass fraction,,$- R_{i}$ stands for net production rate of species $i$ due to chemical reactions (here $0), \frac{\mathrm{kg}}{\mathrm{m}^{3} \cdot \mathrm{s}}$, and $S_{i}$ denotes an additional rate of creation defined by the UDF (here the condensation source rate), $\frac{\mathrm{kg}}{\mathrm{m}^{3} \cdot \mathrm{s}}$.

The $\vec{J}_{i}$ from the Eq. (1) stands for a mass diffusion, which for turbulent flows is defined as follows

$\vec{J}_{i}=-\left(\rho D_{i, m}+\frac{\mu_{t}}{S c_{t}}\right) \nabla Y_{i}-D_{T, i} \frac{\nabla T}{T}$

where $D_{i, m}$ is the mass diffusion coefficient of the $i-t h$ species in the mixture $m, \frac{\mathrm{m}^{2}}{\mathrm{~s}}, \mu_{t}$ is the turbulent viscosity, $\frac{\mathrm{kg}}{\mathrm{m} \cdot \mathrm{s}}$, $S c_{t}$ stands for the turbulent Schmidt number, -, and the $D_{T, i}$ denotes the turbulent diffusivity, $\frac{\mathrm{kg}}{\mathrm{m}^{3} \cdot \mathrm{s}}$.

The momentum equation is defined as

$\frac{\partial}{\partial t}(\rho \vec{v})+\nabla \cdot(\rho \overrightarrow{v v})=-\nabla p+\rho \vec{g}+\vec{F}$

where $p$ is the static pressure, $\frac{\mathrm{kg}}{\mathrm{m} \cdot \mathrm{s}^{2}}$ and $\rho \vec{g}$ and $\vec{F}$ are gravitational and external body forces, respectively.

The energy balance equation takes the form side of the device (Fig. 1). Hence, the whole geometry of the device needs to be simulated.

The computational domain has been divided into three main parts shown in Fig. 4: inlet part $I$ (orange), heat exchanger steam side $I I$ (blue), and heat exchanger air side III (green). Such an approach allowed for the use of three independent meshes according to different needs. All the three parts were connected by UDFs and boundary conditions. Part $I$ consists of front baffles, grease filters, and the fan boundary conditions. Part $I I$ is a space where steam condenses, while part $I I I$ is just an air outlet zone with an outlet filter.

The front baffles and the grease filters in part $I$ were modelled as a porous zone. The actual pressure drops were provided by additional measurements.

The fan is a complex device to model. As it is not the crucial part of the model, it was decided to test the fan under controlled conditions and replace it by BCs in the model. Location of the fan is shown in Fig. 4.

The heat exchanger (part II in Fig. 4) is equipped with several dozens of internally finned pipes. The exact mesh-

$\frac{\partial}{\partial t}(\rho E)+\nabla \cdot(\vec{v}(\rho E+p))=-\nabla \cdot\left(k_{\text {eff }} \nabla T+\sum_{i} h_{i} J_{i}+(\stackrel{\bar{\tau}}{\tau} \cdot \vec{v})\right)+S_{1}+S_{2}+S_{3}$

where $E=h-\frac{p}{\rho}+\frac{v^{2}}{2}, \frac{m^{2}}{s^{2}}, k_{\text {eff }}$ is the effective thermal conductivity, $\frac{\mathrm{W}}{\mathrm{m} \cdot \mathrm{K}}, h_{i}$ stands for the sensible enthalpy, $\frac{\mathrm{kJ}}{\mathrm{kg}}, S_{1}-S_{3}$ are the additional energy source terms added as the UDF, $\frac{W}{\mathrm{~m}^{3}}$. Here, $S_{1}$ is negative and denotes physical enthalpy of the condensing steam outside the pipe; $S_{2}$ is also negative and stands for the physical enthalpy of the steam condensing on the wall of the HE (steam side); $S_{3}$ is positive heat source term which constitutes the heat transferred from the steam/ air mixture to the coolant air on the air-side of the HE (III).

More specific description of the equations above can be found in Ansys Fluent Theory Guide [25].

The condensation hood is asymmetric and has a complex construction. Both steam inlets are located on one ing of such geometry would need an enourmous number of elements and extremely long computing time. Additional numerical studies showed that around a million elements are necessary for accurate prediction of the pressure loss and a velocity profile inside the single pipe. For this reason, the pipe was analyzed separately. Results from this analysis were used to give an appropriate UDF. Thus, the pipe geometry was replaced by an empty cylinder with a set of boundary conditions accounting for the outflow from the pipe and its cooling performance.

The outlet filter located in the part III was also modelled as a porous zone. As in case of the front baffles and 


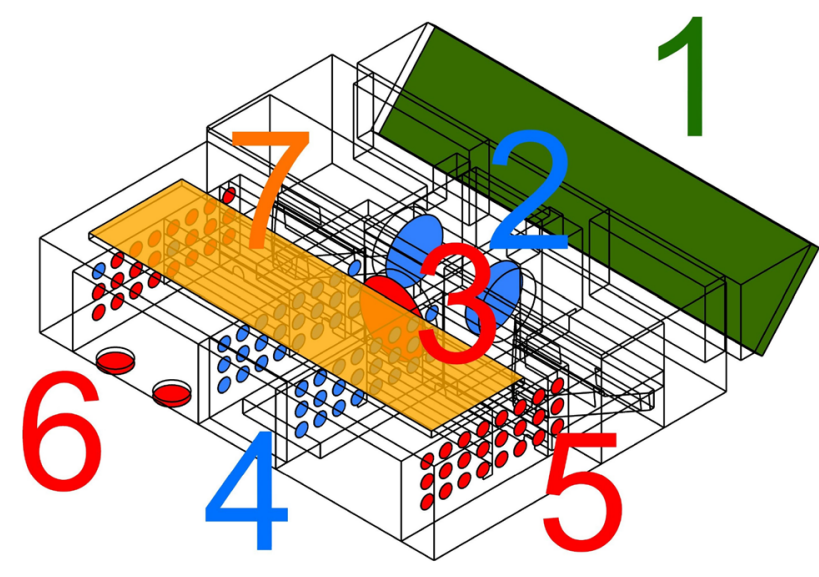

Fig. 5 Boundary conditions. 1-air inlet; 2-fan inlets; 3-fan outlet; 4-pipe inlets; 5-pipe outlets; 6-steam inlets; 7-air outlet

grease filters, additional measurements provided the actual pressure drop of this filter.

(air side).

The above mentioned sub-models together with adapted boundary conditions are now described in the next subsections.

\subsection{Boundary conditions}

The boundary conditions used in the model are presented in Fig. 5. They are numbered from $l$ to 7 . Roman numerals $I$ to III denote the parts into which the computational domain has been divided, as shown in Fig. 4. Number $I-1$ stands for the air inlet with the pressure inlet BC set. Fan inlets $I-2$ force the air flow by using negative pressure. A scaled velocity profile is used at fan outlet $I I-3$, and then the air flows to pipe inlets $I I-4$, where the back pressure is set for each pipe individually. This significantly affects the air flow rates in the pipes. Next, air heated in the pipes leaves them through the pipe outlets $I I-5$. Steam is provided with steam inlets $I I-6$ (half of the steam mass flow rate per each inlet) with a mass flow rate $\mathrm{BC}$. The air leaves the device through air outlet III-7 with a pressure outlet BC.

\subsection{Model of the fan}

The implemented model of the fan is based on fan inlets 2 and fan outlet 3 previously shown in Fig. 5. The air mass flow rate $m$ through the fan is constant, so the sum of flow rates through the fan inlets has to be equal to the flow rate of the fan outlet. Temperature $T$ and humidity $w$ are also taken into account. Both of the results from the balances are then applied to the fan outlet $I I-3$.

While the assumption of uniform profiles of temperature and humidity has no important impact on the fan output, the velocity profile has. Hence, the fan UDF applies a proper velocity profile with use of normal velocity vectors attached to the face (which belongs to fan outlet 3 ) of each cell adjacent to fan outlet 3 . Additional measurements of the installed fan in the condensation hood provided the necessary velocity profile. The measurements were carried out with use of a Pitot's tube in 144 equidistant points. Then, velocity values in these points were bilinearly interpolated to $\approx 1000$ points, that correspond to centers of mesh cells' boundary faces. Interpolation was done with use of a dedicated, in-house algorithm, that utilizes Vandermonde matrix.

\subsection{Model of the pipe: condensation and heat transfer}

The model of the pipes in the heat exchanger (HE) is schematically presented in Fig. 6. Air flows from the air distribution chamber $A 1$, through the pipe $D$ (the geometry of the pipe is reduced to an empty space) to air collector $A 2$. The air flowing from $A l$ flows into the pipe through air inlet 4 ,
Fig. 6 Pipe UDF -scheme. 4-air inlet; 5-air outlet; 6steam; A1-HE air distribution chamber; A2-HE air outlet pocket; B-HE steam zone; $\mathrm{C}$-condensation cell layer; $\mathrm{D}$ - the pipe; $\mathrm{W}$ - pipe wall

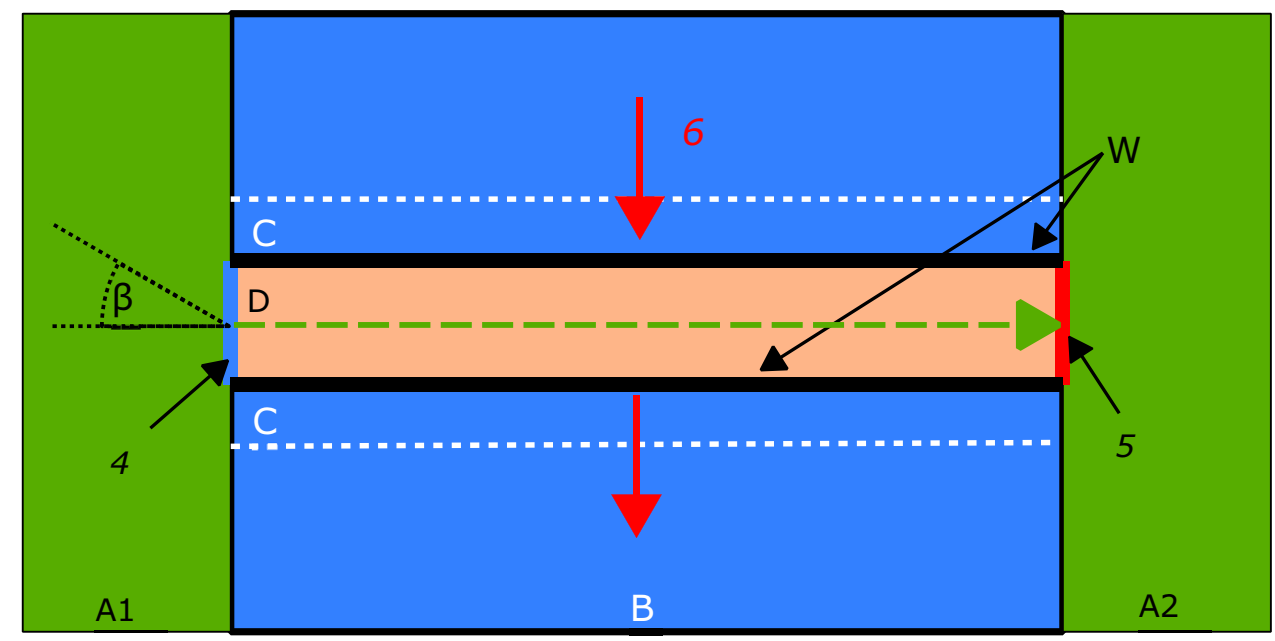


where the pressure outlet $\mathrm{BC}$ is applied and the back pressure set. Next, the air flow rate is translated to the air outlet 5 as mass flow rate. As shown by the red arrows, the steam 6 flows through space $B$ perpendicularly to the pipe.

The moisture content or humidity ratio (mass of moisture per unit mass of dry air) of the air flowing through the heat exchanger is constant. Hence, the moisture content at the pipe inlet 4 is transferred to the pipe outlet 5 . The air mass flow rate through the pipe is also constant. The relative humidity, however, decreases because of the temperature of the air. The temperature increases according to the heat received from the steam. This heat rate is calculated as follows:

$\dot{Q}=\dot{Q}_{\max } w_{H 2 O} \varepsilon_{t} \varepsilon_{s}$

where $\dot{Q}$ stands for the actual heat rate exchanged between the air and the steam, W, $\dot{Q}_{\max }$ is the maximum possible heat rate that can be exchanged by a single pipe, $\mathrm{W}, w_{\mathrm{H} 2 \mathrm{O}}$ is the steam mass fraction in layer $\mathrm{C}$ (see Fig. 4) next to the pipe-which is able to form condensate, and $\varepsilon_{t}$ and $\varepsilon_{s}$ are the correction factors of the air and steam, respectively, with regard to temperature. Both are provided by the external model of the single pipe. When the temperature of the air in the condensation hood is equal to the nominal air temperature in the external single-pipe model, the coefficient $\varepsilon_{t}=1$. If the temperature is higher, $\varepsilon_{t}>1$, and if lower then $\varepsilon_{t}<1$. The same applies to $\varepsilon_{s}$.

The maximum heat rate potential of the pipe, $\dot{Q}_{\max }$, was derived with the use of an external model of a single pipe. It takes the form of a polynomial in terms of the air flow rate under the assumption that the pipe is entirely surrounded by pure steam. The model has been solved for a number of cases at different air flow rates, air inlet angles $\beta$, and air and steam temperatures.

Heat transfer between air in the steam side (if any) and air theoretically flowing through the pipe is implemented as a wall boundary condition defined as a heat flux $q_{\text {wall,pipe }}$

$q_{\text {wall,pipe }}=-w_{\text {air }} \frac{\left(T_{\text {air }}-\bar{T}_{\text {air,pipe }}\right)}{R}$

where $w_{\text {air }}$ is the air mass fraction on the steam side, -, $T_{\text {air }}$ is the air temperature near the wall of the pipe (provided by the C_T Fluent macro), K, $\bar{T}_{\text {airpipe }}$ is mean air temperature in the pipe (note that, the pipe is empty inside so the temperature is calculated based on inlet-outlet temperatures), $\mathrm{K}$, and $R$ stands for the thermal resistance, $\frac{W}{m^{2} \cdot K}$. In the majority cases $w_{\text {air }}$ is close to 0 or the temperature difference is close to 0 and hence, $q_{\text {wall,pipe }}$ contribution to overall heat transfer is negligible.

The pipe's adjacent layer $C$ consists of a single layer of cells located at the pipe's wall $W$ with a wall BC applied. These cells contain an amount of steam that is less than or equal to their volume. Such an approach limits the steam condensation potential and as a consequence the pipe's heat power. Condensation in this case takes place in the layer $C$ by the use of two types of source terms. The first one is a mass source term that is the mass flow of the condensing steam (condensate) defined as follows:

$\dot{m}_{\text {condensate }}=-\frac{\dot{Q}}{h_{f g}^{*} V}$

where $\dot{m}_{\text {condensate }}$ stands for the volumetric condensate mass flow rate, $\mathrm{kg} /\left(\mathrm{s} \mathrm{m}^{3}\right), h_{f g}^{*}$ is the modified latent heat of vaporization of water, $\mathrm{J} / \mathrm{kg}$, and the volume of the layer $C$ (shown in Fig. 6), $\mathrm{m}^{3}$, and $V$ is the volume to which the source is applied. $h_{f g}^{*}$ takes into account condensate subcooling by an additional term consisting of the condensate enthalpy and the temperature decrease below the saturation temperature.

The latter is an energy source rate related to the removed condensate (see Eq. 7). Fluent solves several equations including mass and energy. Applying the source term to the mass equation forces the same term in the species mass fractions equation, and also a proper term in the energy equation expressed by

$\dot{H}_{\text {steam }}=\dot{m}_{\text {condensate }} c_{\text {steam }}\left(T-T_{\text {ref }}\right)$

where $\dot{H}_{\text {steam }}$ denotes steam enthalpy, $\mathrm{W} / \mathrm{m}^{3}, c_{\text {steam }}$ is the specific heat of the steam, $\mathrm{J} /(\mathrm{kg} \mathrm{K}), T$ and $T_{\text {ref }}$ stand for the steam temperature and reference temperature respectively, K.

The temperature at the outlet of the pipe $T_{\text {air,pipe,outlet }}$ of the air flowing through the pipe is calculated according to the equation below and then is applied as the temperature boundary condition at outlet 5

$T_{\text {air,pipe,outlet }}=T_{\text {air,pipe,inlet }}+\frac{\dot{Q}}{c_{\text {air }} \dot{m}_{\text {air,pipe }}}$

where $T_{\text {air,pipe,inlet }}$ is the air temperature at the inlet of the pipe, $\mathrm{K}, c_{\text {air }}$ is a specific heat of the air, $\frac{\mathrm{kJ}}{\mathrm{kg} \cdot \mathrm{K}}$, and $\dot{m}_{\text {air,pipe }}$ denotes mass flow rate of the air $\frac{\mathrm{kg}}{\mathrm{s}}$.

The $T_{\text {air,pipe,inlet }}$ is calculated as a mass weighted average temperature over all cell faces within a given inlet $\mathrm{BC}$ with use of F_T and F_FLUX Fluent macros

$T_{\text {air,pipe,inlet }}=\frac{\sum_{\text {face }}\left(T_{\text {air face }} \dot{m}_{\text {air face }}\right)}{\dot{m}_{\text {air,pipe }}}$

where $T_{\text {air }, \text { ace }}$ is the air temperature at the face belonging to the inlet BC provided by the F_T macro, $\mathrm{K}, \dot{m}_{\text {air.face }}$ stands for the air mass flow rate through the same face provided by the F_FLUX macro, $\frac{\mathrm{kg}}{\mathrm{s}}$.

The overall mass flow rate of the air through the pipe - $m_{\text {air,pipe }}$ is calculated over all cell faces of the inlet BC 
$\dot{m}_{\text {air,pipe }}=\sum_{\text {face }} \dot{m}_{\text {air } f a c e}$

\subsection{Heat exchanger steam side II}

The steam in a vicinity of the HE shell (shown as subdomain II in Fig. 4) also can condense as the shell is surrounded by the air at a lower temperature. As a consequence of temperature difference, the following heat transfer rate may be calculated

$\dot{Q}_{\text {wall,II }}=\frac{A}{R}\left(T-T_{\text {air }, I I I}\right) w_{H_{2} \mathrm{O}}$

where $\dot{Q}_{\text {wall }, I I}$ denotes the heat transfer rate transferred from the steam to the air on the air-side (zones $A l$ and $A 2$ ), $\mathrm{W}, A$ is the surface area of a shell's wall, $\mathrm{m}^{2}, R$ stands for the thermal resistance, $\frac{m^{2} \cdot K}{W}$, and $T_{a i r, I I I}$ is the ambient air temperature on the air-side of the HE, K.

Due to heat transfer rate $\dot{Q}_{\text {wall,II}}$, some amount of the steam can condense, hence an additional near-wall mass source term is defined as

$\dot{m}_{\text {condensate, wall,II,st }}=\frac{\dot{Q}_{\text {wall,II }}}{h_{f g}^{*} V}$

where $\dot{m}_{\text {condensate,wall,II,st }}$ denotes near-wall condensate mass source rate, $\frac{\mathrm{kg}}{\mathrm{m}^{3} \cdot \mathrm{s}}$.

Along with the removed condensate $\dot{m}_{\text {condensate, wall,II,st }}$ an appropriate physical enthalpy has to be subtracted from the energy equation. This is done by the following source term defined similarly to the Eq. (8)

$\dot{H}_{\text {steam,wall,II,st }}=\dot{m}_{\text {condensate, wall,II,st }} c_{\text {steam }}\left(T-T_{\text {ref }}\right)$

\section{II - head exchanger (steam side)}

\section{The pipe}

- Maximal heat transfer rate $\dot{Q}_{\max }$

- Actual heat transfer rate

$\dot{Q}$

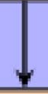

The pipe source terms

- Condensate source rate $\dot{m}_{\text {condensate,st }}$

- Condensed steam enthalpy $\dot{H}_{\text {steam }, s t}$
The wall II (steam side)

- Steam heat transfer rate $\dot{Q}_{\text {wall,II }}$

\section{The wall II source terms}

- Condensate source rate $\dot{m}_{\text {conden sate, wall }, I I, s t}$

- Condensed steam enthalpy $\dot{H}_{\text {steam, wall, } I I, s t}$

The wall III source term

- Heat source rate mixture(II)-air(III) $\dot{Q}_{\text {wall }, I I I, s t}$

\section{III - heat exchanger (air side)}

Fig. 7 Schematic algorithm of the developed condensation and heat transfer model within developed UDF 


\subsection{Heat exchanger air side III}

The heat received from the steam/air mixture in the HE steam side II - needs to be transferred to the air in the air side of the HE (subdomain III in Fig. 4). It is done by additional source term $Q_{\text {wall,III,st }}$ applied to the cells near the walls.

$\dot{Q}_{\text {wall,III,st }}=\frac{\dot{Q}_{\text {wall,total,II-III }}}{V}$

where $\dot{Q}_{\text {wall,total,II-III }}$ is a total heat transfer rate between steam/air mixture in the II and a coolant air in the III, W. In other words: $\dot{Q}_{\text {wall,total,II-III }}$ contains heat transfer steam(II)air(III) from the Eq. (12), heat transfer air(II)-air(III) and heat losses to the environment.

All of the most important elements of the UDF model are schematically presented in Fig. 7. There are two main sets of heat transfer rates and source terms in the heat exchanger steam side II: on the pipe wall and on the HE walls, where the condensate is removed. There is also one source term in the HE air side III, where the heat from the steam/air mixture (II) is transferred to the coolant air on the other side of the wall.

\subsection{Mesh}

Convergence and solution quality still remained the most important factors that had to be satisfied by the mesh. In inlet part $I$ (see Fig. 4) no vital phenomena occur, so there is no need for fine mesh. However, for convergence purposes, the part was meshed with orthogonal elements using the sweep method to the maximum extent possible, as shown in Fig. 8. The only region of tetrahedral elements $A$ is located near small holes connecting part $I$ and part $I I$ and around the fan.

The finest mesh ( $B$ in Fig. 8) were used in the heat exchanger steam side $I I$, where condensation takes place and source terms are applied. This part was almost entirely meshed with use of the sweep method with orthogonal elements of a size up to $5 \mathrm{~mm}$. Part III consists of hexahedral elements of size $\approx 7 \mathrm{~mm}$ generated with use of sweep method as well.

Heat exchanger air side III consists entirely of orthogonal elements (sweep method), slightly larger than in part II.

In case of unsweepable bodies, located in the part $I$ in Fig. 4, a tetrahedral mesh was used.

The entire mesh consists of over 1.1 million elements and over 830 thousands nodes. Such a size allowed for computational time less than 12 hours.

\subsection{Two numerical models}

Once the original device had been simulated and the simulation was validated, a second numerical model was developed. Both geometries are presented here for the sake of clarity, while all the results appear later in the text. The second model shares the whole set up (maintaining intact UDFs) with the previous one. It had, however, some improvements introduced to the heat exchanger part. The

Fig. 8 Mesh in cross-sections. Isometric view

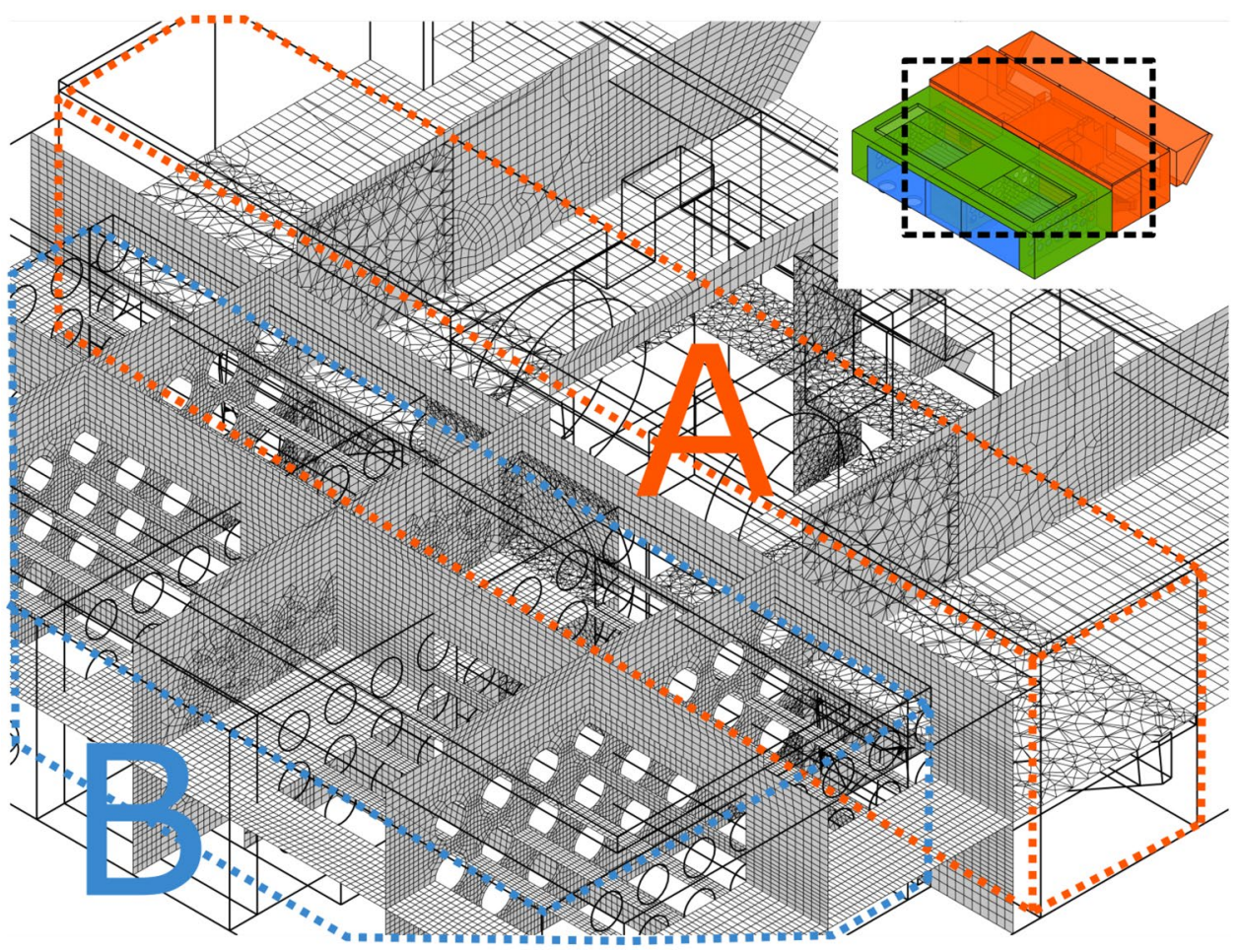


heat exchangers of both models are presented in Fig. 9. In Fig. 9a an original one is shown. It consists of two bundles of pipes 1.a denoted by horizontal orange rectangles. Between the bundles there is an air distribution chamber $D C$ (green), which is supplied with air by the fan 4 . Next, the air flows through the pipes (green arrows) and leaves the main part of the exchanger. Steam inlets 3 introduce steam into the exchanger (blue zone) according to the red arrows. Both bundles are connected with the channel 2.a. The exchanger is equipped with baffles that increase the steam residence time between the pipes. There are four baffles per exchanger: two in the left-hand side bundle ( $L 1$ and $L 2)$ and two in the right-hand side $(R l$ and $R 2)$ as indicated in Fig. 9.

On the right-hand side (Fig. 9b) a modified heat exchanger is presented. Two rows of the pipes $1 . b$ were entirely removed. The first row (the nearest one to the steam inlets 3 ) in order to expand the cross-sectional area of the canal $2 . b$ and the last row due to it having the lowest rate of air flow through the pipes. Baffles $L 1, L 2, R 1$, and $R 2$ were modified as well. The front baffles (from the steam flow rate perspective), $L 1$ and $R 1$, were moved between the two first columns of the pipes, while $L 2$ and $R 2$ remained at their original column-wise positions.
Figure $9 c-f$ presents the side view of both heat exchangers (original and modified one). Figure $9 \mathrm{c}$ and e show the original exchanger - left-hand side and right-hand side bundles, respectively. The red arrow denotes schematically steam propagation into the bundles. Baffles $L 1-R 1$ and $L 2-R 2$ are identical and are located as the Figure indicates. Numerical simulations showed that, rear baffles $L 2$ and $R 2$ have no significant impact on the steam trajectory. Additionally, the lower pipes before the front baffles $L I$ and $R l$ were poorly covered by the steam. Hence, the introduced changes to the second model applied also to the baffles.

Figure $9 \mathrm{~d}$ and $\mathrm{f}$ show the left-hand side and right-hand side bundles of the modified heat exchanger, respectively. Front baffles $L 1$ and $R l$ were moved closer to the steam inlets 3 and located between the first two pipe columns. Rear baffles $L 2$ and $R 2$ were mounted in the same manner as the front ones - at the top. As a lighter gas than air, the steam rises quickly towards the upper part of the exchanger. Hence, mounting both pairs of baffles at the top enabled the steam to be locked between them and among the majority of the pipes. Additionally, the left-hand side baffles $L 1$ and $L 2$ are longer than their right-hand side counterparts by length $L_{e x t}$ shown in Fig. 9d. Such a configuration reduces
Fig. 9 Heat exchangers' overhead view: (a) original construction; (b) modified construction. 1.a-pipes in original HE; $1 . b$ - pipes removed; $2 . a$-original steam channel; $2 . b$ - expanded steam channel; 3-steam inlets; 4air inlet; 5-air distribution chamber; $L 1$-front left baffle; $L 2$ - rear left baffle; $R 1$-front right baffle; $R 2$-rear right baffle.Heat exchangers' side view: (c) original construction left-hand side bundle; (d) modified construction left-hand side bundle; (e) original construction right-hand side bundle; (f) modified construction righthand side bundle. $L_{\text {ext }}-$ left baffles' extension

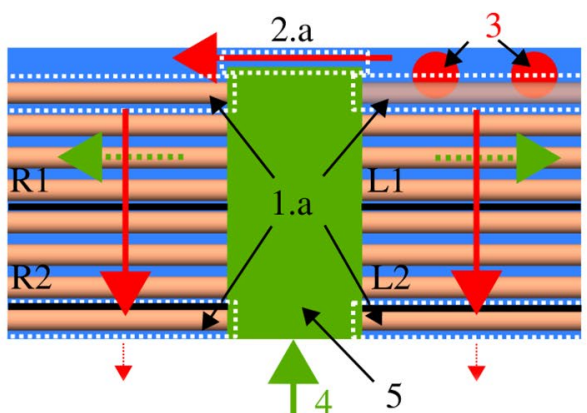

(a)

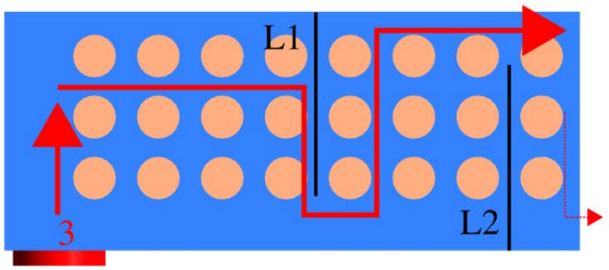

(c)

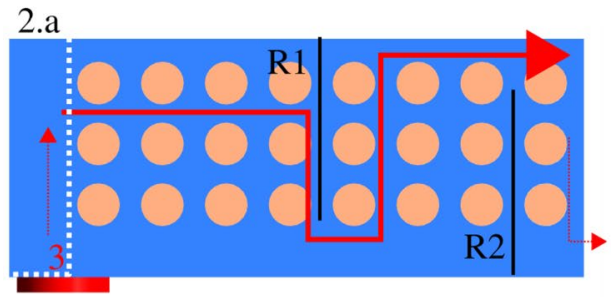

(e)

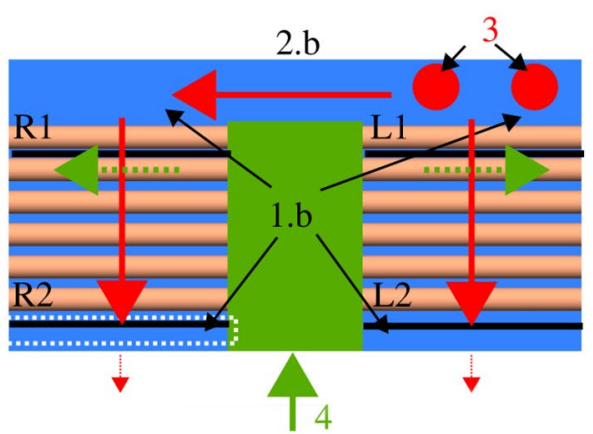

(b)

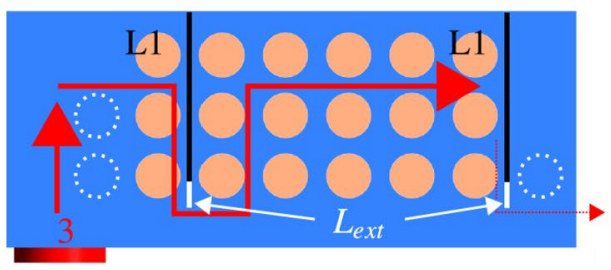

(d)

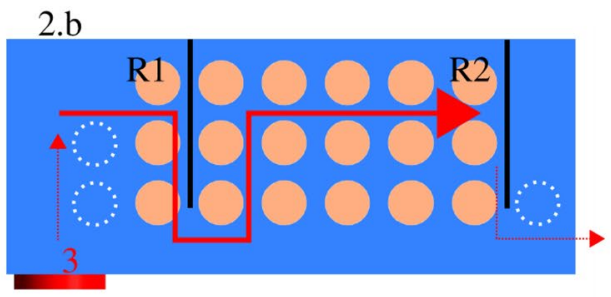


the cross-sectional area available for the steam flow and additionally forces the steam into the right-hand side bundle.

\section{Results and discussion}

A numerical model of the original existing condensation hood was first developed and validated. To impove clarity, original condensation hood and its numerical counterpart are called original construction (OC). A modified model was then prepared based on the gathered results. Once it was done, a prototype of the modified condensation hood was built and tested. This prototype, alongside the modified numerical model, are called modified construction (MC). Both models share a common set up, UDFs, and most parts of the geometry. Therefore, they are presented together and compared with each other in order to get a clear picture of the introduced modifications and their impact on the device's performance.

The velocity fields of both models are presented in Fig. 10. Figure 10a shows the velocity in the original case. The highest velocity is located in the air distribution chamber in the central part of the heat exchanger. The medium velocity zone is in the outlet part 3 (see Fig. 4). There, in peripheral air pockets $A 2$, air streams leaving the pipes can be distinguished. In the inlet part $I$, the velocity field is relatively uniform and symmetrical apart from the fan inlets' surroundings. The magnitude of the velocity in the heat exchanger on the steam side $I I$ is unnoticeable.

A similar situation can be observed in Fig. 10b, which presents the modified model. In this case, however, the air distribution chamber was shorter than in Fig. 10a, but the velocity field remained similar. The number of pipes was reduced by $25 \%$, so local values of the velocity of the air in the air pockets were slightly higher. The inlet parts $I$, in both cases remained unchanged, as did the velocity profile.

In Fig. 10c and d temperature distributions of the original and modified cases respectively, are presented. Only the heat exchanger is included, because inlet part $I$ practically does not participate in the heat exchange. In the air distribution chamber, air is pulled by the fan and has the lowest temperature. The air leaving the pipes is significantly warmer. In the heat exchanger, the highest temperatures are near the steam inlets. The temperature gradually decreases as the steam flows through the bundles. The steam channel extension $2 . b$ (see Fig. 9) had a significant impact on the steam distribution in both bundles, which is confirmed by Fig. 10c and d. In Fig. 10c the left-hand side bundle is noticeably hotter than the other. The situation is different in Fig. 10d, where the broadened channel provided a bigger steam flow to the right-hand side bundle.

Figure 10c also shows the locations of the thermocouples denoted by T1-T8. They were placed in the same manner in the modified prototype to compare both cases with measurements. Thermocouples T1-T4 were mounted in the heat exchanger on the steam side - in the middle of the bundle. $\mathrm{T} 1$ and $\mathrm{T} 3$ were behind the second column of pipes, between upper pipe and the middle one. $\mathrm{T} 2$ and $\mathrm{T} 4$ were behind the fifth column, between the upper and middle one as well. Thermocouples T5-T8 were mounted on the air side located at the fourth pipe column. Thermocouples T6 and T8 were near the outlet of the middle pipe, while $\mathrm{T} 5$ and $\mathrm{T} 7$ were slightly above the upper pipe.

The mass fraction of $\mathrm{H}_{2} \mathrm{O}$ is presented in Fig. 10e and $\mathrm{f}$. In the original construction (Fig. 10e), the steam mass fraction is noticeably higher in the left-hand side bundle than in the right-hand side. An insufficiently wide connection channel limited the amount of steam that could reach the right-hand side bundle. The situation is different in Fig. 10f, where the modified design allowed for a more uniform steam distribution between the two bundles. The steam distributions in both cases corresponded with their temperature counterparts.

The air does not mix with the steam in the outlet part III, so the $\mathrm{H}_{2} \mathrm{O}$ mass fraction remains at the same level in the air distribution chamber as in the air pockets. On the other hand, a quantity of air appears in the heat exchanger $\left(\mathrm{H}_{2} \mathrm{O}\right.$ mass fraction less than 1), pulled from the inlet part $I$ through the holes connecting these two parts.

Original and modified constructions were tested under similar conditions and strictly specified steam flow rates varying from less than $2 \mathrm{~g} / \mathrm{s}$ (cases $\mathrm{A}$ and $\mathrm{C}$ ) to almost 12 $\mathrm{g} / \mathrm{s}$ in case B. This approach allows for a direct comparison of the both constructions in normal and extremal conditions, especially in terms of the condensation efficiency.

- A-laboratory conditions, steam from a $3.4 \mathrm{~kW}$ generator,

- B-laboratory conditions, steam from a $27 \mathrm{~kW}$ generator,

- $\mathrm{C}$-operating conditions, working with a combi-steamer, $100{ }^{\circ} \mathrm{C}$ steam mode.

Case A in regard to a heat load is similar to operation with the combi-steamer (case C). $3.4 \mathrm{~kW}$ corresponds to approximately $1.18-1.29 \mathrm{~g} / \mathrm{s}$ of the steam, depending on the measurement. Additionally, case A is more reliable than case $\mathrm{C}$ due to its precisely controlled test conditions. Case $\mathrm{B}$ constitutes an extremely high heat load the condensation hood will never have to cope with. Nevertheless, it has been included in the research to test the maximum condensation potential of the device $-27 \mathrm{~kW}$ translates into about 11.49 $\mathrm{g} / \mathrm{s}$ of the steam, which constitutes 10 times the nominal steam flow rate provided to the condensation hood. Cooperation with a dedicated combi-steamer is marked as case C characterized by slightly higher steam flow rate of 1.35-1.62 $\mathrm{g} / \mathrm{s}$ compared to the case A, yet less reliable. 


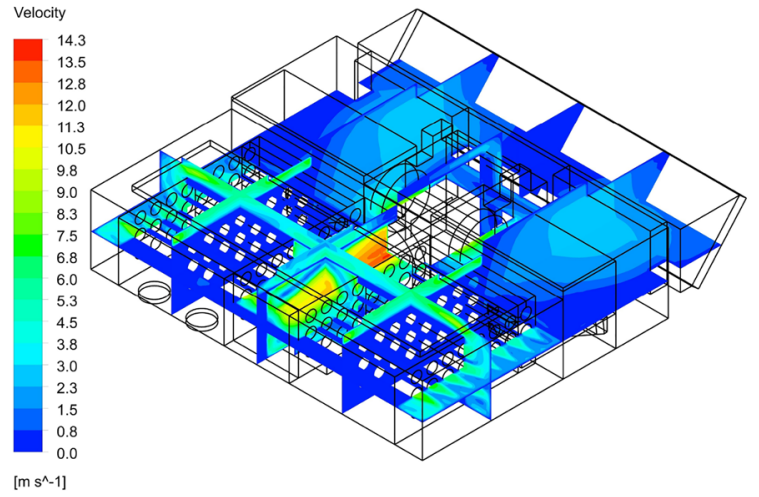

(a)

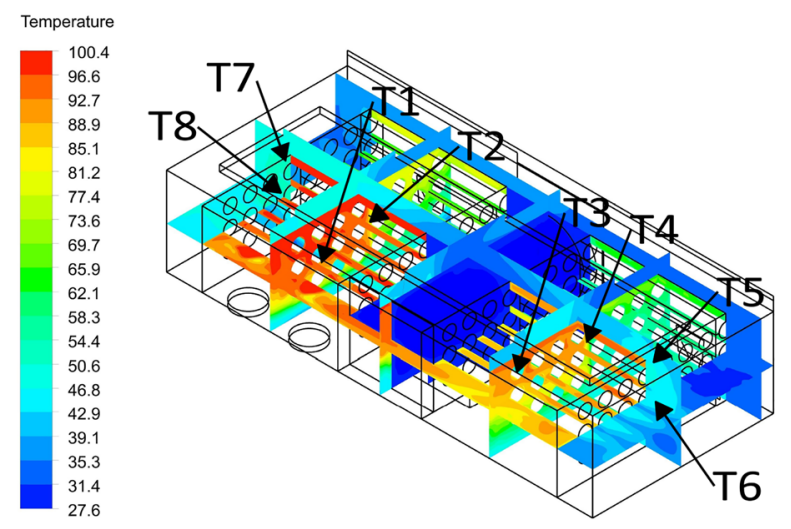

(c)

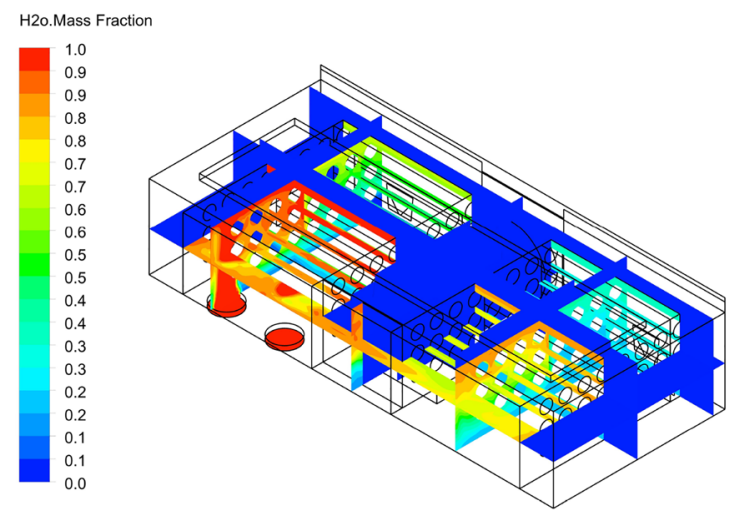

(e)

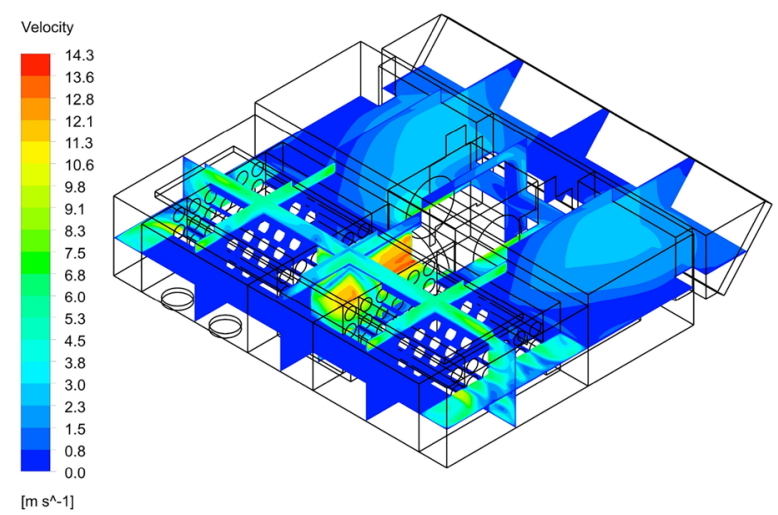

(b)

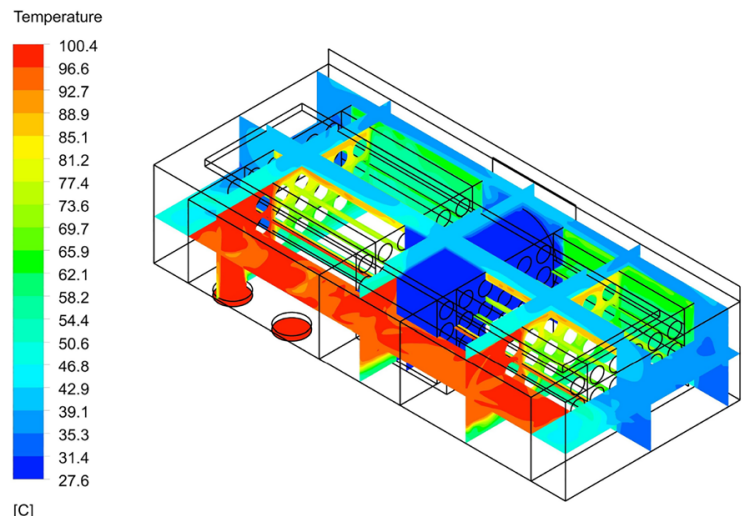

(d)

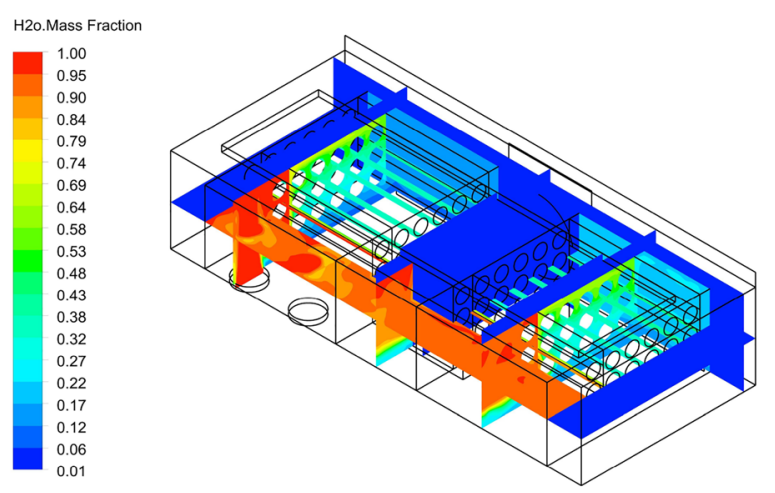

(f)

Fig. 10 Quantity fields: (a, b)—velocity; (c, d)—temperature; (e, f)—steam distribution. (a, c, and e)—original construction; (b, d, and f)— modified construction

The ambient pressure was measured at the beginning and at the end of each measurement. It varied from $98700 \mathrm{~Pa}$ to $100670 \mathrm{~Pa}$ and had negligible impact on the air moisture content calculated from the relative humidity.
Figure 11 contains the measured and numerically obtained temperatures at the outlets of the both examined constructions. Fig. 11a contains values for original construction, while Fig. $11 \mathrm{~b}$ for the modified construction. 
Fig. 11 Outlet temperatures: (a) — OC; (b) - MC; OC—original contruction; $\mathrm{MC}$-modified construction; EXP-experimental value; $C F D$-numerically obtained value

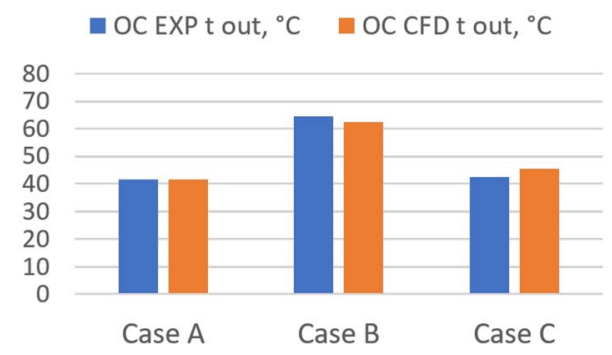

(a)

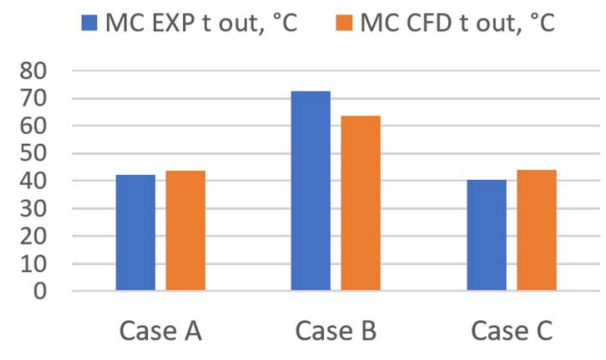

(b)
The temperature concerns the air (the coolant), which mass flow rate varied from $0.184 \mathrm{~kg} / \mathrm{s}$ to $0.188 \mathrm{~kg} / \mathrm{s}$. The highest temperatures were noted in case $\mathrm{B}\left(\right.$ about $70^{\circ} \mathrm{C}$ ), while in the remaining cases approx. $40^{\circ} \mathrm{C}$. Blue and orange bars denoting experimental and CFD values, respectively, are of a similar height - especially for the $\mathrm{OC}$, which means the model accurately predicted the temperatures at the outlet. The highest discrepancy can be noticed in case B for the $\mathrm{MC}$ and accounts for about $10^{\circ} \mathrm{C}$. This discrepancy is most probably caused by short period of measurement and not reaching steady state.

Figure 12 presents a relative humidity of the original construction (shown in Fig. 12a) and the modified construction (shown in Fig. 12b). The numerical model, again, accurately predicted relative humidity values except for the case B for the MC, where the difference accounts for about $15 \%-25 \%$ from the experiment compared to the $40 \%$ from the CFD model. The discrepancies between experimental and CFD relative humidities do not exceed $10 \%$. Obtained relative humidity values under $50 \%$ allow for a statement, that still a significant amount of the water vapour can be diluted in the coolant air. The difference visible for Case B and MC is a result of temperature discrepancy.

The most important parameter indicating the quality of this kind of device is and is the condensation efficiency showed in Fig. 13 and defined as the steam to the condensate mass flow rates ratio [24]. The original construction (OC), presented in Fig. 13.a, already had a high efficiency - about $90 \%$ in cases $A$ and $C$. In case $B$ (high heat load) this parameter dropped to about $27 \%$. The CFD-provided condensation efficiencies in cases $A$ and $C$ are higher by approximately $7 \%$, while case $B$ is lower by about $3 \%$.

The condensation efficiency of the modified construction (MC), shown in Fig. 13b, in cases $A$ and $C$ (normal working conditions), both the experimental- and CFD-provided was over $90 \%$ (except for the experimental value of the case of the $C$ ). In case $B$, the condensation efficiency decreased to around $25 \%$; however, the steam flow rate was in this case about 10 times greater than nominal one.

In case $A$ the modified condensation hood (MC) has a lower condensation efficiency than the original one $(88 \%$ compared to $98 \%$ in Fig. 13. The measurements were conducted in similar conditions, yet the steam flow rates differed by approximately $10 \%$ to the disadvantage of the MC. Nonetheless, the modified condensation hood condensed almost the same amount of the steam $(1.14 \mathrm{~g} / \mathrm{s})$ as the OC $(1.16$ $\mathrm{g} / \mathrm{s})$. Case $B$ showed that the maximum condensation potential decreased from about $3 \mathrm{~g} / \mathrm{s}(\mathrm{OC})$ to $2.4 \mathrm{~g} / \mathrm{s}$ (MC). As a consequence, the condensation efficiency decreased from almost $27 \%$ to about $21 \%$. Due to the difficulties encountered during the measurements with the combi-steamer, the results in case $C$ are not a fully reliable source of information. According to them, the condensation efficiency of the MC dropped from $88 \%$ (OC) to about $74 \%$ (case $C$, blue bars in Fig. 13). This result is unlikely considering other cases: $A$ where condensation efficiency loss does not exceed $10 \%$ (with $\approx 10 \%$ higher steam flow rate); in case $B$ the condensation efficiency decreased by just $6 \%$ (measurements were carried out in similar conditions and the steam flow rates were almost identical. Nevertheless, as it can be seen in
Fig. 12 Outlet relative humidities: (a)—OC; (b)—MC; OCoriginal contruction; $\mathrm{MC}$ modified construction; EXP experimental value; $\mathrm{CFD}$ numerically obtained value

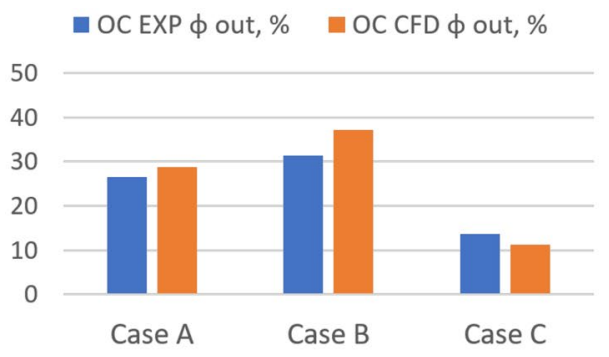

(a)

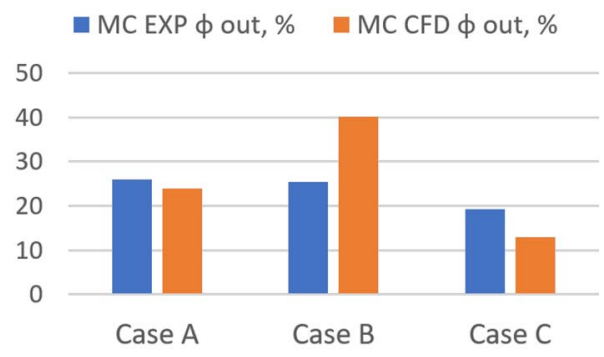

(b) 
Fig. 13 Condensation efficiency: (a)—OC; (b)—MC; $\mathrm{OC}$-original contruction; MC-modified construction; EXP experimental value; CFD—numerically obtained value

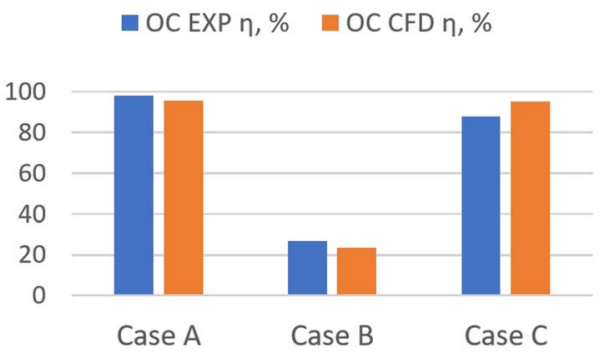

(a)

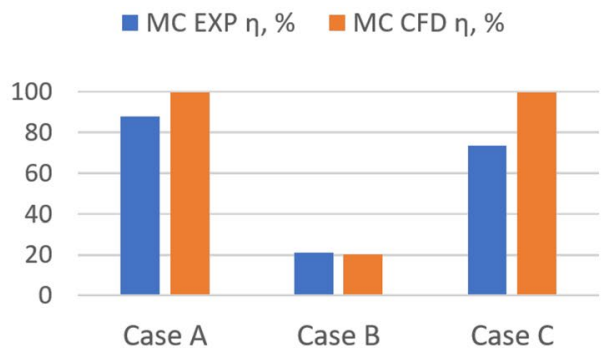

(b)
Fig. 13 for all considered cases always the OC hass slightly better experimental condensation efficiency than the MC.

Figure 14 contains temperatures at the points indicated in Fig. 10c provided by the measurements EXP and by the CFD simulation of the original construction (OC). Figure 14a presents points T1-T4 located on the steam side in the heat exchanger, while Fig. 14b presents points T5-T8 located on the air side of the HE. Each data series - EXP and CFD for a given point consists of a three bars: one per tested case $A, B$, and $C$. For example, to compare experimental and numerical temperatures at point $\mathrm{T} 1$ in the case $A$, blue bars (first from the left) T1 EXP and T1 CFD should be taken into account. In this case, temperature T1 CFD is overestimated by the model by about $30^{\circ} \mathrm{C}$. The temperatures relatively correspond with each other, excluding point $\mathrm{T} 4$ EXP in case $B$, where apparently, the thermocouple failed, and as a consequence the temperature value is not included. In other cases, the highest discrepancies occurred at points
T1-T4 located on the steam vents side of the heat exchanger. For such a situation, two factors can be responsible. Firstly, in the experiment each of these points stands for a thermocouple placed inside the heat exchanger shell. In the CFD model, the temperatures are the average of the closest surroundings of the potential thermocouple location, because it is difficult to unambiguously define the actual location of the thermocouple. Temperature gradients, transient character of the flow, and location uncertainty - could all contribute to the discrepancies. Secondly, condensation could take place on the thermocouples (especially T1-T4), having an effect on the measured values. The CFD model did not reflect accurately the experimental local temperature values, however the general tendency is fulfilled. The temperature on the steam side (points T1-T4) are in general significant higher than on the air side (points T5-T8).

Figure 15 presents the temperatures inside the heat exchanger (parts $I I$ and $I I I$ ) of the modified condensation
Fig. 14 Temperatures in the OC: (a) — HE steam side; (b) $\mathrm{HE}$ air side; OC—original contruction; HE-heat exchanger; T1-T8 - measurement points
Fig. 15 Temperatures in the MC: (a)—HE steam side; (b) - HE air side; MC - modified contruction; $\mathrm{HE}$ - heat exchanger; T1-T8-measurement points
- Case A Case B Case C

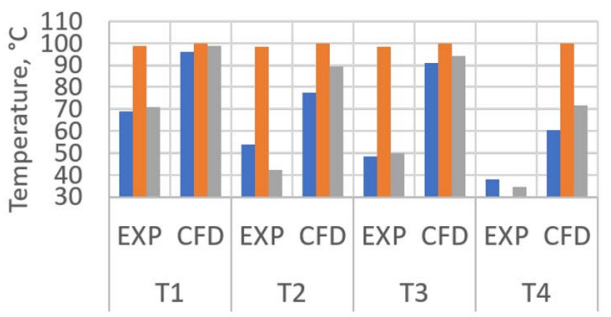

(a)

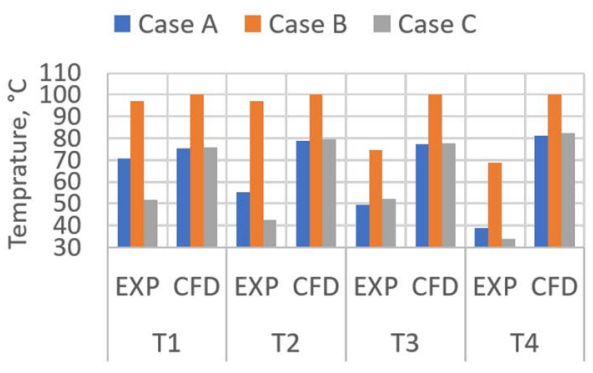

(a)

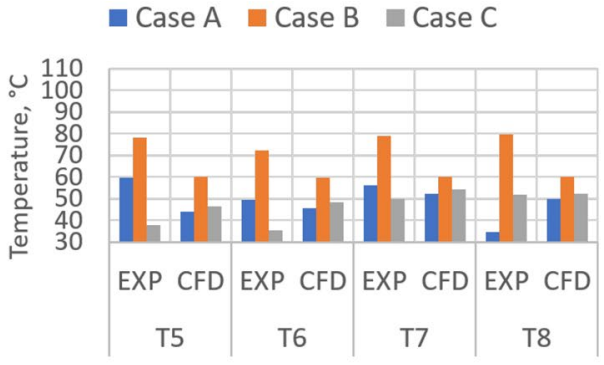

(b)

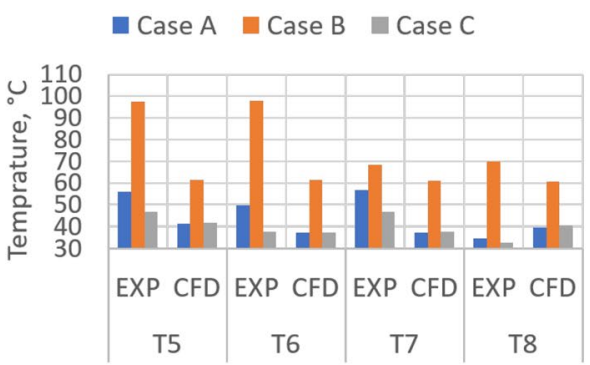

(b) 
hood (MC). Figure 15a presents temperatures at points T1-T4 located on the steam side of the HE, while Fig. 15b presents temperatures at points T5-T8 on the air side of the HE. All of the points T1-T8 were located in the same manner as in the original construction, however it was very difficult to place them exactly at the same locations. The results, again, are characterized by high discrepancies between experimental and numerical values, especially noticeable in cases $A$ and $C$ for the T1-T4 points, and do not allow for any reliable conclusions.

\section{Summary and conclusions}

Two numerical models of two condensation hood's were developed and validated in this work. Main task of the condensation hood is steam condensation inside its heat exchanger. Modelling of such a heat exchangers (condensers) includes two-phase flows with phase change - a very demanding issues in terms of computational time, effort and solution convergence. Due to time limits imposed by the project, an innovative approach regarding condensation and heat transfer in the heat exchanger had to be proposed. Proposed method, additionally, allows for a significant reduction of number of elements of the mesh, while maintaining robustness and high accuracy. However, it can be used in case of relatively small steam flow rates, because the condensate is directly removed from the domain instead of being modelled. Such an approach enables a single phase model without phase change, what affects computational time and improves convergence.

The model of the fan included the transportation of the air and water content from the fan inlet to the outlet. Additionally, a velocity profile provided by the measurements was applied.

The second introduced model is the model of the condensation. It included the pipes and a set of energy and mass source terms. The pipes were removed from the geometry and replaced by a set of boundary conditions and UDFs. Such an approach forced an introduction of the condensation model (because the pipes geometrically no longer existed), which involved the transport of air (with its water content) from the pipe inlet to the outlet, the transfer of energy from the condensing steam to the air in the pipe, the calculation of air temperature at the outlet, and the removal of condensed steam from the domain. This allowed for significant numerical mesh and computational effort reduction.

The developed numerical model of the original condensation hood provided results that are in good agreement with the measurements. The introduced geometrical and process simplifications allowed for the relatively fast attainment of numerical results. It also allowed for the identification and development of potential modifications of the heat exchanger, which included the removal of $25 \%$ of the pipes, an improved location of the heat exchanger baffles, and considerable better usage of the right-hand side pipe bundle.

Modifications developed in previous analysis were implemented and then examined in the numerical model of the modified condensation hood. Once the model had been completed and the modifications' potential confirmed, the prototype of the device was built in order to validate the model. Such an approach allowed for the building of one prototype including only the most promising modifications, saving a lot of time and effort. The numerical results were slightly more optimistic than their experimental counterparts. Nonetheless, the modified device is comparable to the original one in terms of condensation efficiency, despite the reduction of the heat transfer surface by $25 \%$. This means that the modified condensation hood is no worse and at the same time much cheaper.

Funding Financial assistance was provided by grant no. POIR.03.02.01-18-0019/15-00 funded by the Polish Agency for Enterprise Development, Poland, and is here acknowledged.

Availability of data and material The data is available on demand.

Code availability Developed pipe, condensation and heat transfer models are available on demand.

\section{Declarations}

Conflicts of interest On behalf of all authors, the corresponding author states that there is no conflict of interest.

Open Access This article is licensed under a Creative Commons Attribution 4.0 International License, which permits use, sharing, adaptation, distribution and reproduction in any medium or format, as long as you give appropriate credit to the original author(s) and the source, provide a link to the Creative Commons licence, and indicate if changes were made. The images or other third party material in this article are included in the article's Creative Commons licence, unless indicated otherwise in a credit line to the material. If material is not included in the article's Creative Commons licence and your intended use is not permitted by statutory regulation or exceeds the permitted use, you will need to obtain permission directly from the copyright holder. To view a copy of this licence, visit http://creativecommons.org/licenses/by/4.0/.

\section{References}

1. Lane D (2013) ONE FOR ALL. Cater Hotelk 203(4799):56-58

2. Henny Penny Corp (2007) Combi cooking

3. Rapp BE (2017) Chapter 29 - Computational Fluid Dynamics. Elsevier, Oxford

4. Whalley R, Ebrahimi KM (2018) Heat exchanger dynamic analysis. Appl Math Model 62:38-50, 10

5. Egidi N, Giacomini J, Maponi (2018) Mathematical model to analyze the flow and heat transfer problem in U-shaped geothermal exchangers. Appl Math Model 61:83-106, 9 
6. Chhay M, Dutykh D, Gisclon M, Ruyer-Quil C (2017) New asymptotic heat transfer model in thin liquid films. Appl Math Model 48:844-859, 8

7. Genić SB, Jaćimović BM, Milovančević UM, Ivošević MM, Otović MM, Antić MI (2018) Thermal performances of a "black box" heat exchanger in district heating system. Heat and Mass Transfer/Waerme- und Stoffuebertragung 54(3):867-873, 3

8. Dehbi A, Janasz F, Bell B (2013) Prediction of steam condensation in the presence of noncondensable gases using a CFD-based approach. Nucl Eng Des 258:199-210, 5

9. Vyskocil L, Schmid J, Macek J (2014) CFD simulation of airsteam flow with condensation. Nucl Eng Des 279:147-157, 11

10. Rifert V, Sereda V, Solomakha A (2019) Heat transfer during film condensation inside plain tubes. Rev Theor Res 11

11. Kim D-K (2016) Thermal optimization of internally finned tube with variable fin thickness. Appl Therm Eng 102:1250-1261, 6

12. Huq M, Huq AMA, Rahman MM (1998) Experimental measurements of heat transfer in an internally finned tube. Int Commun Heat Mass Transfer 25(5):619-630, 7

13. Wang QW, Lin M, Zeng M (2009) Effect of lateral fin profiles on turbulent flow and heat transfer performance of internally finned tubes. Appl Therm Eng 29(14-15):3006-3013, 10

14. Peng H, Liu L, Ling X, Li Y (2016) Thermo-hydraulic performances of internally finned tube with a new type wave fin arrays. Appl Therm Eng 98:1174-1188, 4

15. Launder BE, Spalding DB (1974) The numerical computation of turbulent flows. Comput Methods Appl Mech Eng 3(2):269-289, 3

16. Loyseau XF, Verdin PG, Brown LD (2018) Scale-up and turbulence modelling in pipes. J Petrol Sci Eng 162:1-11, 3

17. Borhani SM, Hosseini MJ, Ranjbar AA, Bahrampoury R (2019) Investigation of phase change in a spiral-fin heat exchanger. Appl Math Model 67:297-314, 3
18. Wang QW, Lin M, Zeng M, Tian L (2008) Computational analysis of heat transfer and pressure drop performance for internally finned tubes with three different longitudinal wavy fins. Heat and Mass Transfer/Waermeund Stoffuebertragung 45(2):147-156, 12

19. Yunus AC (2007)Heat Transfer: A practical approach. McGrawHill Series in Mechanical Engineering, Boston [etc.], 3rd edition

20. Rezk K, Forsberg J (2014) A fast running numerical model based on the implementation of volume forces for prediction of pressure drop in a fin tube heat exchanger. Appl Math Model 38(24):58225835,12

21. Bashir AI, Everts M, Bennacer R, Meyer JP (2019) Single-phase forced convection heat transfer and pressure drop in circular tubes in the laminar and transitional flow regimes. Exp Thermal Fluid Sci 109:12

22. Wang YH, Zhang JL, Ma ZX (2018) Experimental study on single-phase flow in horizontal internal helically-finned tubes: The critical Reynolds number for turbulent flow. Exp Thermal Fluid Sci 92:402-408, 4

23. Zeitoun O, Hegazy AS (2004) Heat transfer for laminar flow in internally finned pipes with different fin heights and uniform wall temperature. Heat and Mass Transfer/Waerme- und Stoffuebertragung 40(3-4):253-259

24. Tokarski M, Ryfa A, Bulinski P, Rojczyk M, Ziarko K, Nowak AJ (2020) Mathematical model and measurements of a combisteamer condensation hood. Arch Thermodyn 41(1):125-149

25. Ansys Inc. Ansys ${ }^{\circledR}$ (2013) Academic Research CFD, Release 15.0, Help System, Fluent Theory Guide

Publisher's Note Springer Nature remains neutral with regard to jurisdictional claims in published maps and institutional affiliations. 